\title{
A CONTROLLED PROSPECTIVE TRIAL OF THE PROPHYLACTIC EFFECT OF A SINGLE DOSE OF IVERMECTIN AGAINST ONCHOCERCA VOLVULUS
}

\author{
BOUSSINESQ M.* \& CHIPPAUX J.-P.**
}

\section{Summary :}

A clinical trial was conducted in Cameroon in order to evaluate in humans the possible effect of a single dose of ivermectin $1150 \mathrm{\mu g}$ per $\mathrm{kg}$ ) on the pre-adult stages of Onchocerca volvulus. The incidence of the skin microfilariae was measured in two groups of patients who initially had negative biopsies, and who were subsequently treated, immediately after the seasonal peak of transmission of $O$. volvulus, either with a combination of ivermectin + ferrous sulphate, or with ferrous sulphate alone. One year after the treatment, i.e. 14 months after the start of the transmission period, the proportion of patients with positive skin biopsies, and their mean microfilarial loads, did not differ significantly between the two groups. Thus a single dose of ivermectin does not seem to have any perceptible prophylactic effect against $O$. volvulus.

KEY WORDS : onchocerciasis, Onchocerca volvulus, ivermectin, clinical trial prophylaxis, humans, Cameroon.

F Tor more than 10 years onchocerciasis control has been based upon large-scale distribution of ivermectin. This drug has a direct and rapid effect on the microfilariae ( $\mathrm{mf}$ ) of Onchocerca volvulus, which are paralysed, and then drift passively along the lymphatic vessels up to the lymph nodes, where they are destroyed (Darge et al., 1991; Duke et al., 1991; Vuong et al., 1992). Besides this, ivermectin has a more longer-term effect by suppressing, for several months, the production of $\mathrm{mf}$ by the adult female worms. The drug does not seem to affect the embryogenesis (Chavasse et al., 1992), but it causes the developed $\mathrm{mf}$ to accumulate in large numbers in the uteri, before degenerating in situ (Awadzi et al., 1986).

Although the effects of ivermectin on the $\mathrm{mf}$ and the adult stages of $O$. volvulus are well documented, relatively little information is available on whether the drug has what is commonly called a "prophylactic" effect, a term which refers to a lethal or a moult-inhibiting

\footnotetext{
* Laboratoire mixte IRD-CPC d'Epidémiologie et de Santé publique, Centre Pasteur du Cameroun, BP 1274, Yaoundé, Cameroun.

${ }^{* *}$ Institut de Recherche pour le Développement (IRD), BP 1386, Dakar, Sénégal.

Correspondance : M. Boussinesq.

Tél. : (237) 233584 - Fax : (237) 231564

E-mail: orstom.cpc@camnet.cm
}

Résumé : ESSAI PROSPECTIF CONTRÔLÉ SUR L'EFFET PROPHYLACTIQUE D'UNE DOSE UNIQUE D'IVERMECTINE CONTRE ONCHOCERCA VOLVULUS

Un essai thérapeutique a été mené au Cameroun pour évaluer l'éventuel effet, chez l'homme, d'une dose unique d'ivermectine (150 $\mathrm{\mu g}$ par kg) sur les stades pré-adultes d'Onchocerca volvulus. L'incidence de la microfilarodermie a été mesurée dans deux groupes de patients présentant initialement des biopsies négatives et traités, juste après le pic saisonnier de transmission

$d^{\prime} O$. volvulus, soit par ivermectine + sulfate de fer, soit par sulfate de fer seul. Un an après le traitement, soit 14 mois après le début de la période de transmission, le pourcentage de sujets présentant des microfilaires dermiques et la moyenne des charges microfilariennes n'étaient pas significativement différents dans les deux groupes. La prise d'une dose unique d'ivermectine ne semble donc pas provoquer d'effet prophylactique perceptible sur Onchocerca volvulus.

MOTS CLÉS : onchocercose, Onchocerca volvulus, ivermectine, essai thérapeutique, prophylaxie, hommes, Cameroun.

activity against the third or fourth stage larvae (L3s and L4s), or a lethal action on the immature adult worms. First studies, carried out in vitro, have demonstrated that ivermectin kills the L3s of $O$. lienalis and inhibits their moult from L3 to L4 (Court et al., 1985; Lok et al., 1987). Following these results, Taylor et al. (1988) performed an in vivo study, whose objective was to evaluate the prophylactic effect of ivermectin against O. volvulus, and especially to compare the activity of the drug on the L3s and L4s of this species; eighteen chimpanzees were experimentally infected with L3s of O. volvulus, and then assigned to three groups: six animals were treated with a single dose of ivermectin $(200 \mu \mathrm{g} / \mathrm{kg})$ immediately after inoculation, six others received the same dose 28 days after inoculation, and six were left untreated; the results obtained suggested that "ivermectin may have a partial in vivo effect against the L3s of $O$. volvulus but has no effect against later larval stages". The first observations in humans were reported by Chavasse et al. (1992), who compared the proportion of immature adult $O$. volvulus found in nodules of patients treated either with placebo, or with five six-monthly doses of ivermectin; the authors did not find any difference, and concluded that ivermectin treatment did not prevent the development of L3s into adults. However, in another stage of the 
same trial, the proportion of young adult worms was found to be lower in a group of patients having received only a single dose of ivermectin, than in a similar group which had received five six-monthly treatments. The authors concluded that "the most likely explanation is that multiple doses of ivermectin have a partial chemoprophylactic effect reducing the development of infective larvae to young adults" (Kläger et al., 1993). Since then, no further study was performed in humans, but the prophylactic effect of frequent doses of ivermectin on Onchocerca sp. was recently evaluated in Northern Cameroon, using an animal model: the development of $O$. ochengi nodules was compared in two groups of calves, both naturally exposed to the parasite, but one having been left untreated, and the other having received monthly doses of ivermectin for 21 months. At the end of the trial, none of the 15 treated calves had developed nodules, whereas five of the six untreated ones had done so; this demonstrated that ivermectin, when given every month, has a prophylactic effect against O. ochengi (Tchakouté et al., 1999).

In this context of conflicting observations, we performed a controlled prospective trial aiming at evaluating, in the field, the effect of ivermectin on the pre-adult stages of O. volvulus, especially the L4s. For this purpose, we compared the incidence of $O$. volvulus microfilaridermia in two groups of persons, who presented no skin $\mathrm{mf}$ at the outset of the trial but were then exposed naturally to transmission. One group was treated with a standard dose of ivermectin, and the other with a non-antiparasitic drug.

\section{PATIENTS AND METHODS}

\section{STUDY AREA}

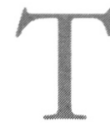
the study area was chosen in accordance with two main criteria. The first was that the inten-

L sity of transmission had to be high enough, so that the incidence of infection would be relatively important, and any eventual differences between the two groups would be perceptible within a relatively short time after treatment. The second was that the transmission had to show marked seasonal variation, so that a large proportion of the patients would be exposed during a limited period of time to a great number of L3s and would subsequently be harbouring a large number of the pre-adult stages of $O$. volvulus. In these circumstances, investigation of a prophylactic effect of ivermectin would be achieved by giving the drug at the peak of the transmission season or at a very short interval thereafter. The study was carried out in the Mbam Valley of the Cameroon Republic, where preliminary parasitological surveys had shown that the prevalence of onchocerciasis was very high in most of the villages (Boussinesq et al., 1992). A longitudinal entomological survey, including catching and dissection of blackflies during one year, had shown that the main local vector of $O$. volvulus was Simulium squamosum s.s., and that the monthly transmission potentials in the area were at their maximum between February and April (Barbazan et al., 1998). In order to get a sufficient number of patients with negative skin biopsies, we decided to perform the trial in Yambassa, which is a large village in the area, where most of the residents were farmers and thus exposed to the bites of infective Simulium vectors during their everyday activities.

\section{SELECTION OF PATIENTS}

The period of the preliminary parasitological examinations to identify persons eligible for the trial, and the date of treatment, were chosen taking into account the peak transmission period, and the presumed course of development of the parasite. It is known that the moult of L3 to L4 occurs three-five days after infestation (Bianco et al., 1989; Bain et al., 1998) and, following observations on $O$. lienalis, it was estimated that the moult of L4 to immature adults occurs 1.5-2.5 months later (Bianco \& Müller, 1982). However, a follow-up of antibody activities against various antigens in experimentally-infected monkeys suggested that the final moult from L4s to immature adults occurs 3.5 to 5 months post-infection (Eberhard et al., 1991). From a) this information, b) assuming that the course of development of the parasite in the monkeys might be a little delayed, when compared with that in the natural human host, and c) our knowledge of the peak transmission period in the area (see above), we estimated that the maximum number of L4s present in the human population would be between February and June. We therefore decided to perform the pre-treatment parasitological examinations in March 1992, and to give the treatments in April, i.e. some 2.5 months after the beginning of the high transmission period, at a time when most of the L4s would have not moulted to the adult stage.

The parasitological examinations were done during the last week of March on 994 persons aged 5 years and above. A clinical examination was done to ensure that no palpable onchocercal nodules were present. Two standardized skin biopsies (one at each iliac crest) were then taken from each person using a $2 \mathrm{~mm}$ Holth-type corneo-scleral punch, and after 24 hours of incubation in saline, they were examined for emerged $\mathrm{mf}$. A total of 149 persons presented neither nodules, nor $\mathrm{mf}$ in the skin, and were thus eligible for the trial. Those persons who were found positive were treated with ivermectin (Mectizan ${ }^{\circledR}, 6 \mathrm{mg}$ tablets), and then excluded from the trial. 


\section{TREATMENT}

The 149 eligible persons were divided randomly into two groups, after stratification on the basis of sex and age. One group (control group) was to be treated with ferrous sulphate tablets (two generic tablets of $200 \mathrm{mg}$ ), and the other (named IVM group) with a combination of ferrous sulphate (two generic tablets of $200 \mathrm{mg}$ ) and ivermectin (Mectizan ${ }^{\circledR}, 6 \mathrm{mg}$ tablets) at the standard dose of $150 \mu \mathrm{g} / \mathrm{kg}$. The treatments were given in April, two weeks after the parasitological examinations, and taking into account the usual exclusion criteria for ivermectin treatment (pregnancy, poor state of health). Amongst the 149 eligible patients, five did not participate in the treatment because of refusal or presence of an ivermectin exclusion criterion. In all, 73 persons received ivermectin plus ferrous sulphate, and 71 only ferrous sulphate. Eventual side-effects to treatment were followed-up during the two next days.

\section{MEASURE OF THE INCIDENCE}

\section{OF MICROFILARIDERMIA AND ANALYSIS}

The date of post-treatment control was chosen taking into account information concerning the prepatent period for $O$. volvulus. The results of a follow-up of subjects negative for $O$. volvulus infection, who were exposed to one season of transmission, and then protected from subsequent infestations by anti-vectorial activities, have shown that a significant incidence of microfilaridermia occurs 7-12 months after the season of peak infectivity (Prost, 1980). Studies conducted on experimentally-infected chimpanzees (Duke, 1980), and on patients who had received effective macrofilaricidal treatment and were then naturally re-infected while living in an area of ongoing transmission (Duke, 1968), suggested that the prepatent period ranges from 10 to 20 months. Based on these data, we decided to perform the re-examinations 14 months after the start of the high transmission period, i.e. in April 1993.

All the participants in the trial were invited for this control, and the parasitological examinations were done using the same methods as during the pre-treatment survey. All the patients with positive skin biopsies were subsequently treated with ivermectin.

The proportions of patients with positive skin biopsies at the control examination were compared using the $\chi^{2}$ test, and the distributions of the microfilarial counts were compared using the Wilcoxon-Mann-Whitney test.

\section{RESULTS}

$\mathrm{T}$ The level of endemicity in Yambassa was assessed using the two indicators recommended by the World Health Organization: the age and sex standardized prevalence of skin $\mathrm{mf}$ (Moreau et al., 1978), and the Community microfilarial load (Remme et al., 1986). The values obtained for these two indicators were $88.2 \%$ and $37.9 \mathrm{mf}$ per skin biopsy, respectively, which confirmed that the intensity of transmission in the village was suitable to lead to a high incidence of microfilaridermia.

Amongst the 144 patients included in the trial, 126 accepted to participate in the April 1993 control examinations, including 64 in the IVM group, and 62 in the control group (Table I). The numbers of persons found to have positive skin biopsies at that time were 15 and 16 , respectively ( 23.4 and $25.8 \%$ ), in the IVM and the control groups. The incidence rates in the two groups were not significantly different $(P=0.75)$. The geometric mean of the counts in the positive persons were 2.2 and $2.7 \mathrm{mf}$ per biopsy, respectively, in the IVM and the control groups. The distribution of the

\begin{tabular}{|c|c|c|c|c|c|}
\hline & & \multicolumn{2}{|c|}{ Control group } & \multicolumn{2}{|c|}{ IVM group } \\
\hline & & Males & Females & Males & Females \\
\hline \multirow[t]{5}{*}{ Age class: } & $5-9$ years & 15 & 26 & 16 & 22 \\
\hline & $10-14$ years & 9 & 7 & 10 & 10 \\
\hline & $15-29$ years & 0 & 2 & 1 & 1 \\
\hline & $30-49$ years & 0 & 1 & 1 & 0 \\
\hline & $\geq 50$ years & 1 & 1 & 0 & 3 \\
\hline \multicolumn{6}{|c|}{ Results at the control examinations: } \\
\hline & No $(\%) \mathrm{Mf}+{ }^{1}$ & \multicolumn{2}{|c|}{$16(25.8)$} & \multicolumn{2}{|c|}{$15(23.4)$} \\
\hline & Range in Mf+ subjects ${ }^{2}$ & \multicolumn{2}{|c|}{$0.5-22$} & \multicolumn{2}{|c|}{$0.5-18.5$} \\
\hline & Median load in Mf + subjects $^{2}$ & \multicolumn{2}{|c|}{2.7} & \multicolumn{2}{|c|}{2.0} \\
\hline & Geometric mean of the loads in Mf+ subjects ${ }^{2}$ & \multicolumn{2}{|c|}{2.7} & \multicolumn{2}{|c|}{2.2} \\
\hline
\end{tabular}

${ }^{1} \mathrm{Mf}+=$ subjects with positive skin biopsies at the control examination

${ }^{2}$ values in number of microfilariae per biopsy.

Table I. - Results of skin examination for Onchocerca volvulus microfilariae in patients who had initially negative skin biopsies, and who had been treated 12 months previously either with ferrous sulphate (control group), or with a combination of ivermectin $(150 \mu \mathrm{g} / \mathrm{kg})+$ ferrous sulphate (IVM group). 
counts did not differ significantly between the two groups $(P=0.57)$. Only four persons (two in each group) showed microfilarial loads above $10 \mathrm{mf}$ per biopsy, and the highest one ( $22 \mathrm{mf}$ per biopsy) was recorded in a patient belonging to the IVM group.

\section{DISCUSSION}

T The present trial was designed to evaluate whether ivermectin, when given at a single dose of $150 \mu \mathrm{g} / \mathrm{kg}$ just after the transmission period, could be effective as a prophylactic drug. Unfortunately, our results suggest either that it was not the case, or that, should this effect exist, it would not be perceptible in practical conditions. Even so, our results are consistent with the parasitological and serological studies performed on chimpanzees treated with ivermectin either at the day of infection with $O$. volvulus (at a time when only L3s are present), or 28 days after (when probably only L4s are present), and which have led to the conclusion that the drug is effective on the L3s, and not on the L4s (Taylor et al., 1988; Chandrashekar et al., 1995).

Indeed, one cannot ignore the possibility that the $\mathrm{mf}$ observed in April 93 in the group treated with ivermectin could be the results of L3s transmitted either more than two-three months before the treatment (and maybe even during the previous high transmission season, one year before), or just after the dose. However, should the drug have been effective against the L4s, it seems to us that this would have led to a significant difference between the two groups, both in the proportion of $\mathrm{mf}$ positive persons, and in the mean microfilarial loads.

It is well known that ivermectin has a prophylactic activity against several species of filariae. In particular, it is active against both L3s and L4s of Dirofilaria immitis and Dipetalonema vitae, and the L3s of Litomosoides sigmodontis (Campbell, 1982). The demonstration of an effect of ivermectin on the pre-adult stages of O. volvulus in humans would have had some important consequences in terms of possible future applications of the drug. First, in those areas where the transmission of the parasite has been interrupted by anti-vectorial activities, an eventual recrudescence of transmission could be controlled by the implementation, within the weeks following its detection, of large scale ivermectin treatments of the populations exposed to re-infection. A second application of such an effect, would be the prophylactic treatment of persons coming temporarily into an area endemic for onchocerciasis. The results obtained on the cattle parasite $O$. ocheng $i$ (Tchakouté et al., 1999) suggest that monthly treatments could also have a prophylactic effect against
O. volvulus. However, such a regimen in humans might raise safety problems and would be difficult to put into effect on a large scale.

Further studies should be conducted in other areas to confirm the present results obtained in Central Cameroon and, owing to the conflicting results obtained with repeated six-monthly doses in Sierra Leone (Chavasse et al., 1992; Kläger et al., 1993), it might be interesting to develop trials evaluating the possible prophylactic effect of three- or six-monthly regimens of ivermectin. However, one should keep in mind that, besides the very beneficial consequences which would be associated with such a prophylactic effect, the latter might perhaps also have the major inconvenience of selecting resistant parasites at an early stage of the developmental cycle in man, before the multiplicative macrofilarial stage. Should the mechanisms of resistance to ivermectin be similar in the pre-adult stages and the $\mathrm{mf}$, this would have very negative consequences.

\section{ACKNOWLEDGEMENTS}

T The authors wish to thank all the residents of Yambassa who accepted to participate in the study, and Dr. P. Richard and Mr. DemangaNgangue for their help in the field. We are grateful to Dr. B.O.L. Duke for critically reading of the manuscript. This study was funded by the Institut de Recherche pour le Développement (IRD, ex-Orstom).

\section{REFERENCES}

Awadzi K., Dadzie K.Y., Schulz-Key H., Gilles H.M., Fulford A.J. \& AzIZ M.A. The chemotherapy of onchocerciasis XI. A double-blind comparative study of ivermectin, diethylcarbamazine and placebo in human onchocerciasis in Northern Ghana. Annals of Tropical Medicine and Parasitology, 1986, 80, 433-442.

Bain O., Wanji S., Enyong P., Petit G., Noireau F., Eberhard M.L. \& WAHL G. New features on the moults and morphogenesis of the human filaria Loa loa using rodent hosts. Consequences. Parasite, 1998, 5, 37-46.

Barbazan P., Escaffre H., Mbentengam R. \& Boussinesq M. Étude entomologique sur la transmission de l'onchocercose dans une zone de transition forêt-savane du Cameroun. Bulletin de la Société de Pathologie exotique, 1998, 91, 178-182.

BIANCO A.E. \& MülLER R.L. Experimental transmission of Onchocerca lienalis to calves, in: Parasites - Their World and Ours. Proceedings of the $5^{\text {th }}$ International Congress of Parasitology, Toronto. Molecular and Biochemical Parasitology (supplement), 1982, 349.

Bianco A.E., Mustafa M.B. \& Ham P.J. Fate of developing larvae of Onchocerca lienalis and $O$. volvulus in micro- 
pore chambers implanted into laboratory hosts. Journal of Helminthology, 1989, 63, 218-226.

Boussinesq M., Demanga-Ngangue, Richard P., Lélé D., Cot S. \& Chippaux J.P. Étude clinique et parasitologique de l'onchocercose dans huit villages de la vallée du Mbam (Province du Centre, Cameroun). Bulletin de liaison et de documentation de l'OCEAC, 1992, 100, 26-31.

CAMPBELL W.C. Efficacy of the avermectins against filarial parasites: a short review. Veterinary Research Communications, $1982,5,251-263$.

Chandrashekar R., Van Swinderen B., Taylor H.R. \& Weil G.J. Effect of ivermectin prophylaxis on antibody responses to Onchocerca volvulus recombinant antigens in experimentally infected chimpanzees. International journal for Parasitology, 1995, 25, 983-988.

Chavasse D.C., Post R.J., Lemoh P.A. \& Whitworth J.A.G. The effect of repeated doses of ivermectin on adult female Onchocerca volvulus in Sierra Leone. Tropical Medicine and Parasitology, 1992, 43, 256-262.

Court J.P., Bianco A.E., Townson S., Ham P.J. \& Friedheim E. Study on the activity of antiparasitic agents against Onchocerca lienalis third stage larvae in vitro. Tropical Medicine and Parasitology, 1985, 36, 117-119.

Darge K., Lucius R., Monson M.H., Behrendsen J. \& BüTtNer D.W. Immunohistological and electron microscopic studies of microfilariae in skin and lymph nodes from onchocerciasis patients after ivermectin treatment. Tropical Medicine and Parasitology, 1991, 42, 361-367.

DukE B.O.L. The effects of drugs on Onchocerca volvulus. 1. Methods of assessment, population dynamics of the parasite and the effects of diethylcarbamazine. Bulletin of the World Health Organization, 1968, 39, 137-146.

Duke B.O.L. Observations on Onchocerca volvulus in experimentally infected chimpanzees. Tropenmedizin und Parasitologie, 1980, 31, 41-54.

Duke B.O.L., Soula G., Zea-Flores G., Bratthauer G.L. \& Doumbo O. Migration and death of skin-dwelling Onchocerca volvulus microfilariae after treatment with ivermectin. Tropical Medicine and Parasitology, 1991, 42, 25-30.

Eberhard M.L., Dickerson J.W., Boyer A.E., Tsang V.C.W., Zea-Flores R., Walker E.M., Richards F.O., ZeA-Flores G. \& STROBERT E. Experimental Onchocerca volvulus infections in mangabey monkeys (Cercocebus atys) compared to infections in humans and chimpanzees (Pan troglodytes). American Journal of Tropical Medicine and Hygiene, 1991, 44, 151-160.

Kläger S., Whitworth J.A.G., Post R.J., Chavasse D.C. \& DownHAM M.D. How long do the effects of ivermectin on adult Onchocerca volvulus persist? Tropical Medicine and Parasitology, 1993, 44, 305-310.

LoK J.B., Pollack R.J. \& Donnelly J.J. Studies on the growthregulating effects of ivermectin on larval Onchocerca lienalis in vitro. Journal of Parasitology, 1987, 73, 80-84.

Moreau J.P., Prost A. \& Prod'hon J. Essai de normalisation de la méthodologie des enquêtes clinico-parasitologiques sur l'onchocercose en Afrique de l'Ouest. Médecine Tropicale, 1978, 38, 43-49.

Prost A. Latence parasitaire dans l'onchocercose. Bulletin of the World Health Organization, 1980, 58, 923-925.
Remme J., Ba O., Dadzie K.Y. \& Karam M. A force-of-infection model for onchocerciasis and its applications in the epidemiological evaluation of the Onchocerciasis Control Programme in the Volta River basin area. Bulletin of the World Health Organization, 1986, 64, 667-681.

Taylor H.R., Trpis M., Cupp E.W., Brotman B., Newland H.S., Soboslay P.T. \& Greene B.M. Ivermectin prophylaxis against experimental Onchocerca volvulus infection in chimpanzees. American Journal of Tropical Medicine and Hygiene, 1988, 39, 86-90.

Tchakouté V.L., Bronsvoort M., Tanya V., Renz A. \& Trees A.J. Chemoprophylaxis of Onchocerca infections: in a controlled, prospective study ivermectin prevents calves becoming infected with O. ochengi. Parasitology, 1999, 118, 195-199.

Vuong P.N., Traoré S., Wanji S., Diarrassouba S., Balaton A. $\&$ BAIN O. Ivermectin in human onchocerciasis: a clinicalpathological study of skin lesions before and three days after the treatment. Annales de Parasitologie Humaine et Comparée, 1992, 67, 194-196.

Reçu le 15 février 2001 Accepté le 12 juin 2001 